\section{La Belle Indifference}

Natalie Dattilo

Department of Psychiatry, Indiana University

School of Medicine, Indianapolis, IN, USA

\section{Synonyms}

Belle indifference

\section{Definition}

La belle indifference is defined in DSM- 5 as a "lack of concern about the nature or implications of the symptom" and is listed as an associated feature supporting the diagnosis of conversion disorder (APA 2013, p. 320). Extant neurobiological models converge on the conceptualization of conversion symptoms as involuntary responses to threat reflecting errors in body state information processing and representation (Kozlowska 2005). Theories suggesting frontal lobe hypoactivation as an explanation for apathy and indifference have also been proposed (Spence et al. 2000) as well as theories suggesting a link to right hemispheric dysfunction (Stone et al. 2006).

\section{Cross-References}

- Anosodiaphoria

- Anosognosia

- Apathy

\section{References and Readings}

American Psychiatric Association. (2013). Diagnostic and statistical manual of mental disorders: DSM-5. Washington, DC: American Psychiatric Association.

Kozlowska, K. (2005). Healing the disembodied mind: Contemporary models of conversion disorder. Harvard Review of Psychiatry, 13, 1-13.

Spence, S. A., Crimlisk, H. L., Cope, H., et al. (2000). Discrete neurophysiological correlates in prefrontal cortex during hysterical and feigned disorder of movement. Lancet, 355, 1243-1244.

Stone, J., Smyth, R., Carson, A., Warlow, C., \& Sharpe, M. (2006). La belle indifference in conversion symptoms and hysteria. British Journal of Psychiatry, 188, 204-209. 